\title{
Regulation of angiotensin II type 1 receptor expression in ovarian cancer: a potential role for BRCA1
}

\author{
Fang-Fang $\mathrm{Bi}^{1}$, Da $\mathrm{Li}^{1 *}$, Chen $\mathrm{CaO}^{2}$, Chun-Yan $\mathrm{Li}^{3}$ and Qing Yang ${ }^{1^{*}}$
}

\begin{abstract}
Background: Both BRCA1 and angiotensin II type 1 receptor (AGTR1) play a critical role in ovarian cancer progression. However, the crosstalk between BRCA1 and AGTR1 signaling pathways remains largely unknown.

Methods: BRCA1 promoter methylation was analyzed by bisulfite sequence using primers focused on the core promoter region. Expression levels of BRCA1 and AGTR1 were assessed by immunohistochemistry and real-time PCR. Regression analysis was used to examine the possible relationship between BRCA1 and AGTR1 protein levels. Knockdown or overexpression of BRCA1 was achieved by using a lentiviral vector in 293 T cells and SKOV3 ovarian carcinoma cells, and primary non-mutated and BRCA1-mutated ovarian cancer cells.

Results: BRCA1 dysfunction (BRCA1 mutation or hypermethylated BRCA1 promoter) ovarian cancer showed decreased AGTR1 levels compared to normal tissue. In contrast, AGTR1 expression was increased in non-BRCA1-mutated ovarian cancer. Notably, BRCA1 activation was an effective way to induce AGTR1 expression in primary ovarian cancer cells and a positive correlation exists between BRCA1 and AGTR1 expression in human ovarian cancer specimens.
\end{abstract}

Conclusions: These results indicate that BRCA1 may be a potential trigger involved in the transcriptional regulation of AGTR1 in the development of ovarian cancer.

Keywords: BRCA1, Angiotensin II type 1 receptor, Ovarian cancer

\section{Background}

Ovarian cancer is the most lethal gynecological malignancy in women worldwide [1]. To date, although the exact cause of ovarian cancer remains largely unknown, BRCA mutations are the main known hereditary factor [2], and the risk of ovarian cancer conferred by BRCA mutations can be regulated by both genetic and environmental components [3]. The angiotensin II type 1 receptor (AGTR1) is a novel component of the renin-angiotensin system, and has a direct effect on blood pressure and heart hypertrophy [4]. Recently, AGTR1 has drawn considerable interest, not only in the field of cardiovascular risk but also in several types of gynecological malignancies, such as endometrial cancer $[5,6]$, cervical carcinoma [7], and especially ovarian cancer [8-10]. Accumulating evidence also

\footnotetext{
*Correspondence: leeda@ymail.com; yangq@sj-hospital.org 1 Department of Obstetrics and Gynecology, Shengjing Hospital, China Medical University, Shenyang 110004, China

Full list of author information is available at the end of the article
}

indicates that an increased risk of ovarian cancer and poor patient outcome are associated with AGTR1 expression [9,11]. Our previous study has found that AGTR1 interacts with genetic and environmental factors, which exert a potent effect on the proliferation and survival of the estrogen-induced Ishikawa cell line [12]. Several recent studies also support a possible role for AGTR1 in regulating cell proliferation during cancer development [13]. Additionally, an increasing amount of evidence suggests that BRCA1 haploinsufficiency mutations are more likely to result in cancer, due to an extraordinary ability for clonal growth and proliferation [14]. However, the complex interrelationship between AGTR1 and BRCA1 remains to be elucidated. Therefore, the present study was undertaken to investigate $A G T R 1$ expression from genetic (BRCA1 mutated or not) and epigenetic (BRCA1 promoter methylated or not) aspects in ovarian cancer, and to provide novel insights into the regulatory mechanism of AGTR1.

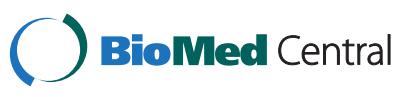

(c) 2013 Bi et al.; licensee BioMed Central Ltd. This is an Open Access article distributed under the terms of the Creative Commons Attribution License (http://creativecommons.org/licenses/by/2.0), which permits unrestricted use, distribution, and reproduction in any medium, provided the original work is properly cited. The Creative Commons Public Domain Dedication waiver (http://creativecommons.org/publicdomain/zero/1.0/) applies to the data made available in this article, unless otherwise stated. 


\section{Methods}

\section{Patients and tissue collection}

This study was approved by the Institutional Review Board at China Medical University. Serous ovarian cancer patients were enrolled between 2010 and 2012, and all patients gave informed consent. Fresh tumor samples, adjacent normal ovarian tissues, ascites and blood samples were obtained at the time of primary surgery before any chemotherapy or radiotherapy. Hematoxylin and eosin staining of the samples for histopathological diagnosis and grading were determined by three staff pathologists using the World Health Organization criteria. All patients were screened for BRCA1 mutations by multiplex polymerase chain reaction (PCR) with complete sequence analysis using methods reported by $\mathrm{Bi}$ and Simard [15,16], Their characteristics are given in Additional file 1: Table S1.

\section{Cell culture and lentiviral transfection}

Primary ovarian cancer cells were obtained from ascites for 15 BRCA1-mutated and 15 non-mutated patients undergoing surgery for ovarian cancer and cultured in RPMI 1640 with $10 \%$ fetal bovine serum (Invitrogen, CA USA) using methods reported by Szlosarek [17]. Primary ovarian cancer cells used in all experiments were passage 2. The proliferation rate is shown in Additional file 2: Figure S1 (methods shown in Additional file 3). Human 293 T cells and SKOV3 ovarian carcinoma cells were maintained in DMEM with $10 \%$ fetal bovine serum (Invitrogen). Each experiment was repeated four times for primary ovarian cancer cells of each patient, 293 T cells and SKOV3 cells. Lentiviral vectors expressing short hairpin RNAs (shRNAs) against BRCA1 (NM_007299) were obtained from GeneChem Co., Ltd (Shanghai, China), and synthesized as follows: Forward: 5 ' CCGGAACCTGTCTCCACAAAGTGTGCTCGAGCACA CTTTGT GGAGACAGGTTTTTTTG-3', and Reverse: 5' -AATTCAAAAAAACCTGTCTCCACAAAGTGTGCT CGAGCACACTTTGTGGAGACAGGTT-3'. The nonsilencing siRNA sequence (TTCTCCGAACGTGTCACGT) was used as a negative control. For overexpression of $B R C A 1$, the open reading frame of BRCA1 (NM_007299) was cloned into the lentiviral vector GV287 (UbiMCS-3FLAG-SV40-EGFP) (GeneChem, Shanghai, China). Transfections were performed using polybrene and enhanced infection solution (GeneChem) according to the manufacturer's recommended protocol. The efficiency of BRCA1 knockdown and overexpression is shown in Additional file 4: Figure S2 (methods shown in Additional file 3).

\section{Real-time quantitative PCR}

Total RNA was extracted using Trizol reagents (Invitrogen) according to the manufacturer's protocol. DNA contamination was removed by adding DNase I (Invitrogen) according to the manufacturer's protocols. Total
RNA was then reverse-transcribed from $2 \mu \mathrm{g}$ of RNA using the PrimeScript RT Master Mix kit (TaKaRa, Dalian, China) and amplified by SYBR Premix Ex TaqTM II (TaKaRa) in a Roche LightCycler 2.0 instrument (Roche Diagnostics, Mannheim, Germany). The specific primer sequences were as follows: AGTR1: 5'-CCTCAGATAATGTAAGCTCATCCAC-3' (F) and 5'-GCTGCAGAGGAAT GTTCTCTT-3' (R); BRCA1: 5'-GGCTATCCTCTCAG AGTGACATTT-3' (F) and 5'-GCTTTATCAGGTTATGT 'TGCATGG-3' (R); GAPDH: 5'-AGGTGAAGGTCGGA GTCA-3' (F) and 5' -GGTCATTGATGGCAACAA-3'(R).

GAPDH mRNA was amplified as an internal control for normalization of each sample. All samples were analyzed in triplicate using the $2^{-\Delta \Delta C T}$ method.

\section{Immunohistochemistry}

The standard SP kit (Zhongshan, Beijing, China) was used for immunohistochemical staining. Briefly, serial $4-\mu \mathrm{m}$ sections were obtained from each paraffin-embedded tissue block. Following deparaffinization and rehydration, sections were subjected to microwave antigen retrieval. The primary antibody were rabbit polyclonal anti-AGTR1 (sc-1173) (1:100; Santa, Cruz Biotechnologies, USA) and rabbit polyclonal anti-BRCA1 (sc-642) (1:100; Santa), and the sections were incubated overnight at $4^{\circ} \mathrm{C}$ with this antibody. 3,3-diaminobenzidine was used as the chromogen. Nuclei were counterstained with hematoxylin, and slides were dried and mounted. Negative controls were incubated with phosphate-buffered saline instead of the antibody. Immunostaining was evaluated by two independent pathologists, blinded to the identity of subject groups. Area quantification was made with a light microscope at a magnification of $400 \times$ and analyzed by ImagePro Plus 6.0 (Media 2 Cybernetics, USA). Intensity of the staining was divided into 10 units.

\section{Bisulfite sequencing for BRCA1 promoter}

All the tissues were used for bisulfite sequencing from the non-BRCA1-mutated cases. Genomic DNA extracted from ovarian cancer and normal ovarian tissue with a TIANamp Genomic DNA kit (Tiangen biotech, Beijing, China) was subjected to bisulfite conversion using the EZ DNA Methylation-Direct kit (Zymo research, Orange, USA) following the manufacturer's instructions; the conversion efficiency was estimated to be at least $99.6 \%$. It was then amplified by nested PCR. After gel purification, cloning and transformation into E. coli Competent Cells JM109 (TaKaRa), ten positive clones of each sample were sequenced to ascertain the methylation patterns of each CpG locus. The following primers were used for $B R C A 1$ gene (Accession number: NG_005905; GRCh37/hg19) promoter: round I, F: 5'-TTGTAGTTTTTTTAAAGAGT-3' and R: 5'-TACTACCTTTACCCAAAACAAAA-3'; and round II, F: 5'-GTAGTTTTTTTAAAGAGTTGTA-3' and 

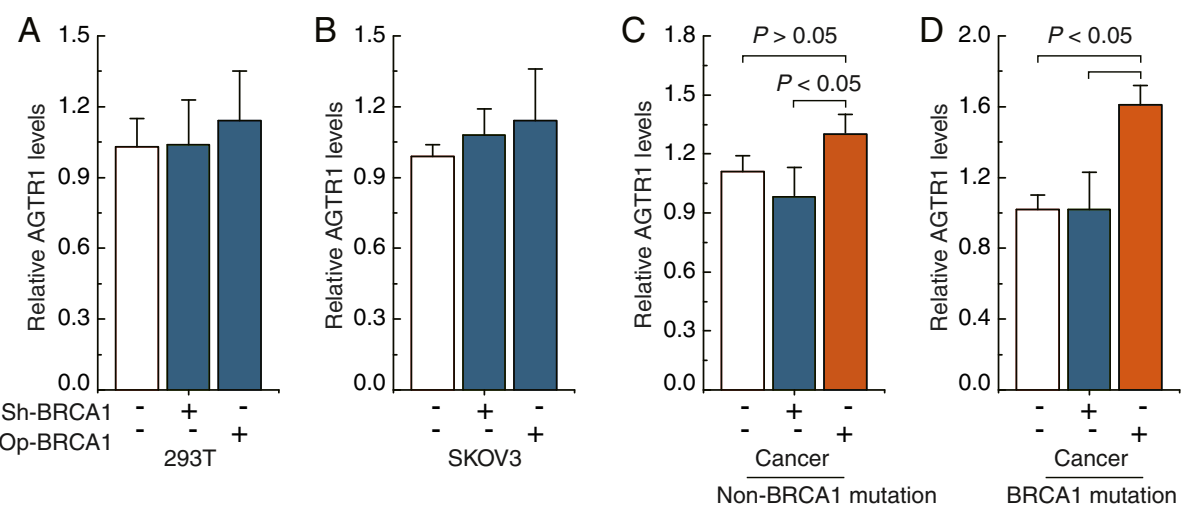

Figure 1 Effects of BRCA1 on AGTR1 expression. A-D, relative AGTR1 mRNA levels after overexpression or knockdown of BRCA1 in 293 T cells, human SKOV3 ovarian carcinoma cells, and primary non-mutated and BRCA1-mutated ovarian cancer cells. Bar graphs show mean \pm SD. Sh, shRNAs; Op, overexpression.

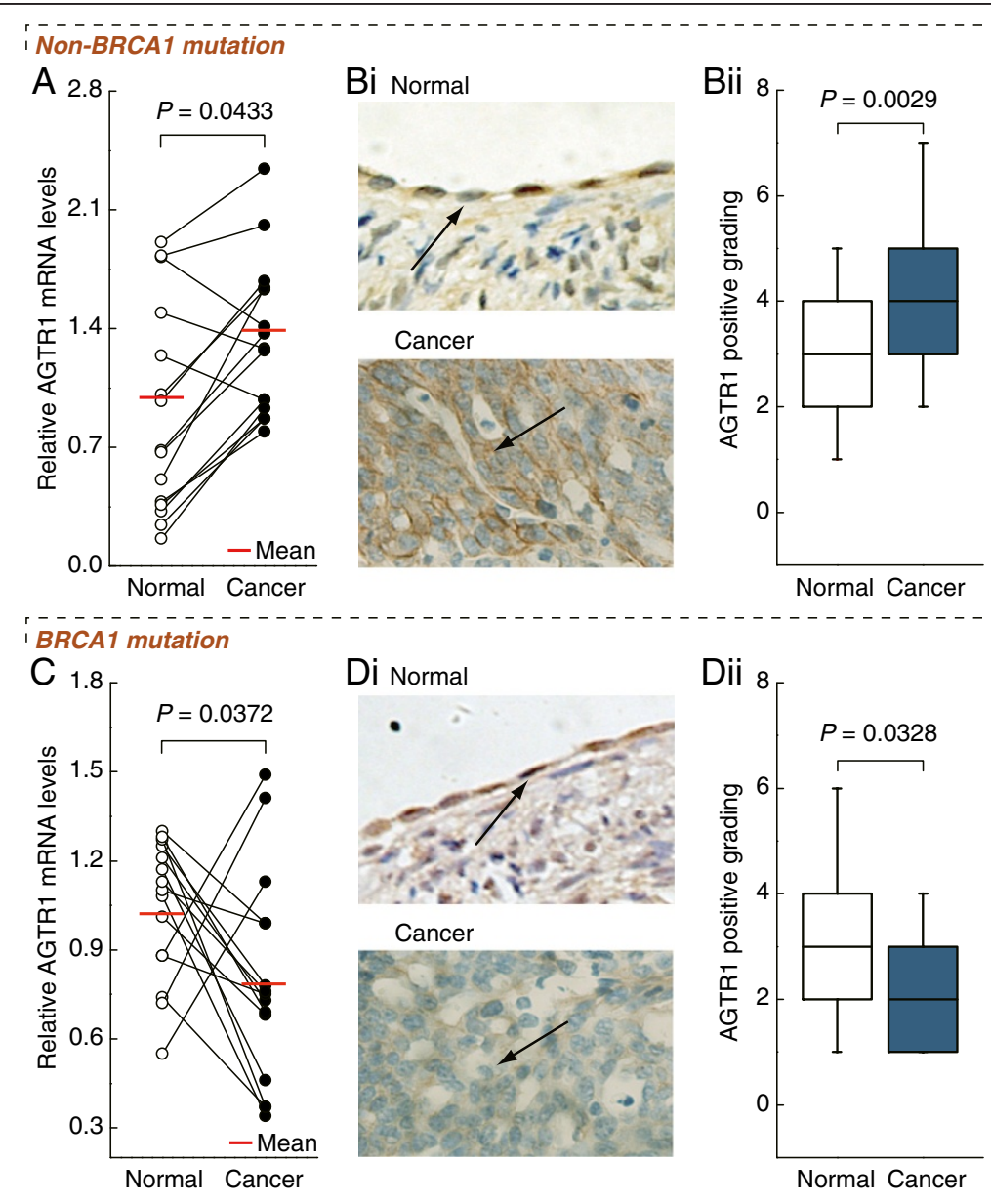

Figure 2 AGTR1 expression patterns in BRCA1-mutated and non-mutated ovarian cancer. A and C, relative AGTR1 mRNA levels were measured in non-mutated or BRCA1-mutated ovarian cancer compared to their adjacent normal tissue, respectively (each group, $\mathrm{n}=15$ ). Bi and Di, sections were subjected to immunostaining for AGTR1 in non-mutated or BRCA1-mutated ovarian cancer compared to their adjacent normal tissue, respectively (each group, $n=15$ ). Arrow shows positive staining for AGTR1 in the membrane. Bii and Dii, summary of the percentages of AGTR1-positive cells from the measurements shown in Bi and Di, respectively. Intensity of the staining was divided into 10 units. Magnification is $400 \times$. 
R: 5'-ACCTTTACCCAAAACAAAAA-3'. The conditions were as follows: $95^{\circ} \mathrm{C}$ for $2 \mathrm{~min}, 40$ cycles of $30 \mathrm{~s}$ at $95^{\circ} \mathrm{C}$, $30 \mathrm{~s}$ at $56^{\circ} \mathrm{C}$ and $45 \mathrm{~s}$ at $72^{\circ} \mathrm{C}$, then $72^{\circ} \mathrm{C}$ for $7 \mathrm{~min}$.

\section{Statistical analysis}

Regression analysis was used to examine the possible relationship between AGTR1 and BRCA1 expression. The data are presented as means \pm SD. Statistical differences in the data were evaluated by Student's $t$ test or one-way ANOVA as appropriate, and were considered significant at $P<0.05$.

\section{Results}

$B R C A 1$ can regulate AGTR1 expression in primary ovarian cancer cells

To confirm the role of BRCA1 in the regulation of $A G T R 1$, the effects of overexpression or knockdown of BRCA1 were observed in 293 T cells, human ovarian carcinoma cell line SKOV3, primary ovarian cancer cells with identified BRCA1 mutations or non-mutation. The results indicated that there were no significant changes in the expression of AGTR1 after overexpression or knockdown of BRCA1 in $293 \mathrm{~T}$ and SKOV3 cells (Figure 1A-B).

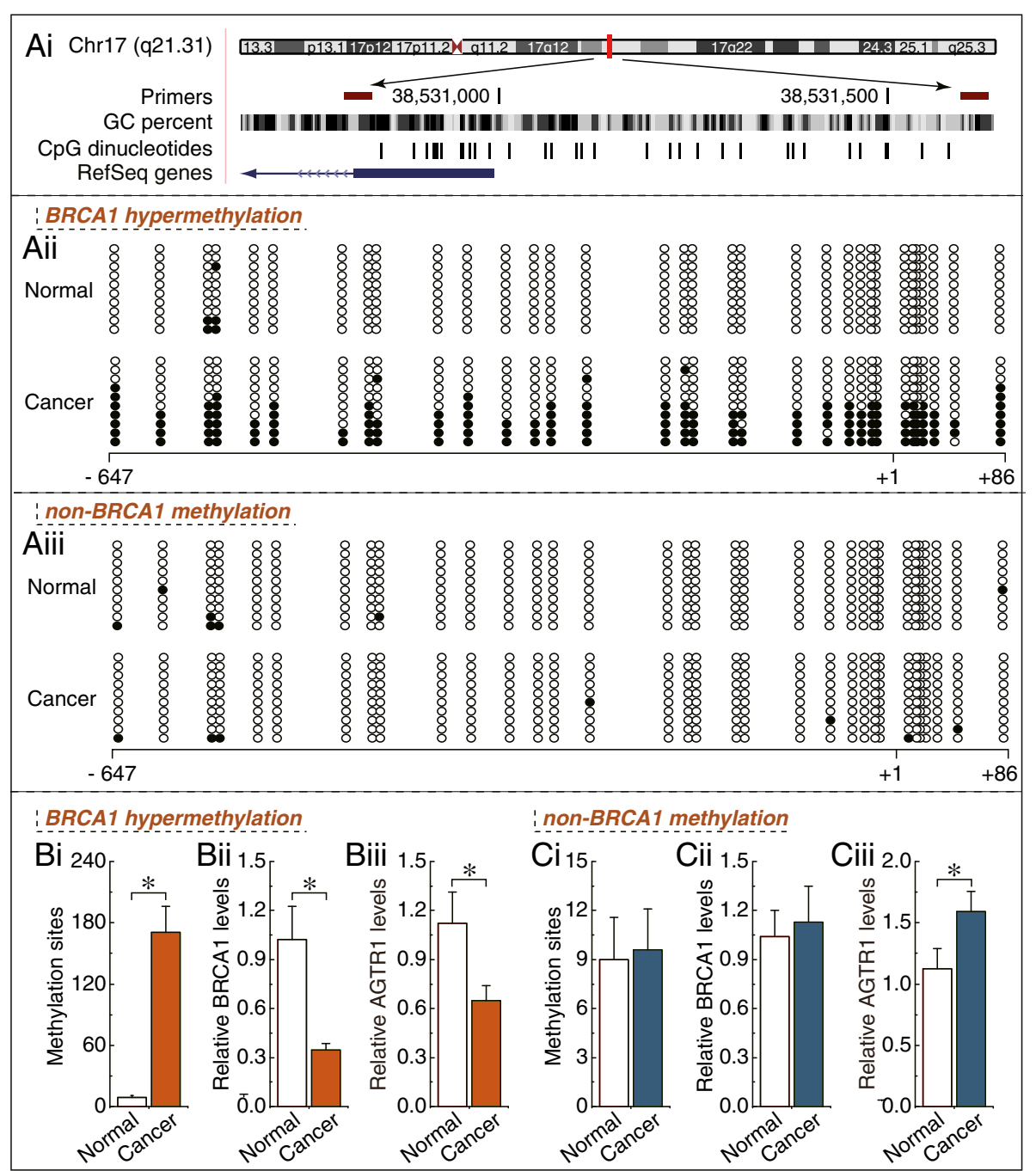

Figure 3 AGTR1 expression patterns in ovarian cancer with hypermethylated promoter-mediated BRCA1 dysfunction. $A \mathrm{i}$, location of $\mathrm{CpG}$ sites in the core promoter region of BRCA1. Genomic coordinates are shown, along with the primer-amplified fragments, GC percentage, location of individual CpG dinucleotides (dashes) and BRCA1 RefSeq gene (exon 1 shown as a blue box and intron shown as an arrowed line). The arrow indicates the direction of transcription. Aii and Aiii, comparative analysis of methylation patterns in the core promoter region of BRCA1 and their adjacent normal tissue (each group, $\mathrm{n}=15$ ). The circles correspond to the $\mathrm{CpG}$ sites denoted by black dashes in Figure 3 Ai. Closed circles, methylation; open circles, unmethylated. Ten individual clones were sequenced for each sample. Bi and Ci, summary of the methylation levels of BRCA1 core promoter from the measurements shown in Aii and Aiii, respectively. Bii and Cii, relative BRCA1 mRNA levels were measured in ovarian cancer with identified hypermethylated or unmethylated BRCA1 promoter compared to their adjacent normal tissue, respectively (each group, $n=15$ ). Biii and Ciii, relative AGTR1 mRNA levels were measured in ovarian cancer in the presence or absence of BRCA1 dysfunction, respectively (each group, $n=15$ ). Bar graphs show mean $\pm S D$. ${ }^{*} P<0.05$ vs. Normal. 
Interestingly, we observed that overexpression of $B R C A 1$ was an effective way to induce an increase in AGTR1 levels in primary non-mutated and BRCA1-mutated ovarian cancer cells, although $A G T R 1$ levels were not sensitive to the BRCA1 knockdown (Figure 1C-D).

\section{Differences in expression patterns of AGTR1 in BRCA1- mutated and non-mutated ovarian cancer}

Real-time PCR and immunohistochemical analysis showed that the levels of AGTR1 mRNA and protein were increased in non-BRCA1-mutated ovarian cancer compared to adjacent normal tissue (Figure $2 \mathrm{~A}$ and $\mathrm{B}, P<0.05$ ). It is, however, interesting to note that BRCA1-mutated ovarian cancer as compared to their adjacent normal tissue reduced the expression of AGTR1 (Figure $2 \mathrm{C}$ and $\mathrm{D}, P<0.05$ ).

\section{Hypermethylated $B R C A 1$ promoter-mediated decreased expression of $B R C A 1$ is correlated with AGTR1 levels} In mammals, promoter methylation at $\mathrm{CpG}$ dinucleotides is an important feature regulating gene expression [18]. Consistent with this idea, we showed that ovarian cancer tissue with a hypermethylated $B R C A 1$ promoter displayed decreased expression of $B R C A 1$ in comparison with adjacent normal tissue (Figure $3 \mathrm{Aii}$ and $\mathrm{Bi}, P<0.05$ ). However, no significant $B R C A 1$ expression differences were observed in ovarian cancer with unmethylated $B R C A 1$ promoter as compared to adjacent normal tissue (Figure 3Aiii and $\mathrm{Ci}, P>0.05)$. Based on these considerations, the low levels of BRCA1 appeared to be mediated by promoter hypermethylation, making this an appropriate model to investigate the physiological relationship between $B R C A 1$ and AGTR1. Notably, the expression levels of $A G T R 1$ were decreased markedly (Figure 3Biii), along with hypermethylated promoter-mediated $B R C A 1$ deficiency in ovarian cancer (Figure 3Bii). In contrast, AGTR1 expression was increased in ovarian cancer tissue (Figure 3Ciii), along with no significant difference of $B R C A 1$ promoter methylation and expression (Figure $3 \mathrm{Ci}$ and $\mathrm{Cii}$ ).

\section{AGTR1 is positively correlated with BRCA1 expression in ovarian cancer samples}

Of particular interest and potential clinical relevance, the relationship between $B R C A 1$ and $A G T R 1$ expression was studied in 63 human ovarian cancer specimens. Our results showed that there is a significant positive association between $B R C A 1$ and $A G T R 1$ protein expression (Figure $4 \mathrm{~A}$ and $\mathrm{B}$ ).

\section{Discussion}

In this study, we report for the first time an association between BRCA1 and AGTR1 status in ovarian cancer: (i) $A G T R 1$ expression was increased in non-BRCA1-mutated ovarian cancer, but BRCA1 dysfunction (such as via $B R C A 1$ mutation or promoter hypermethylation) was associated with decreased $A G T R 1$ levels; (ii) there was a positive correlation between BRCA1 and AGTR1 expression in

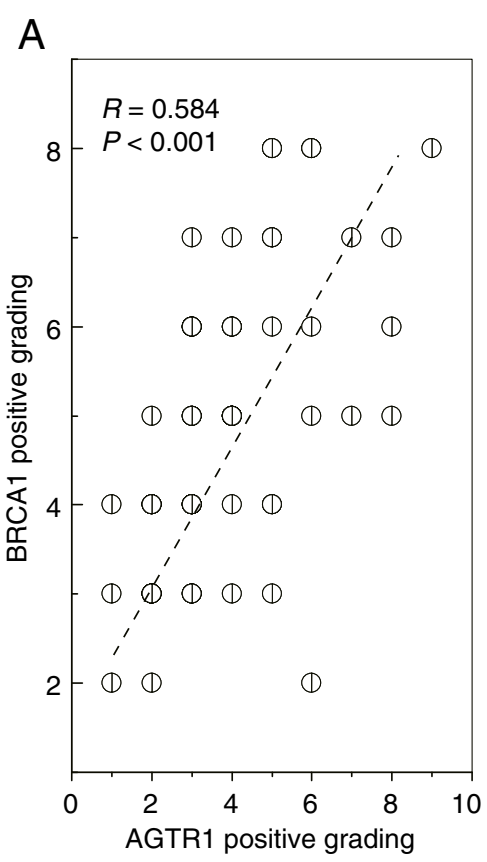

\section{B $\quad$ BRCA1}
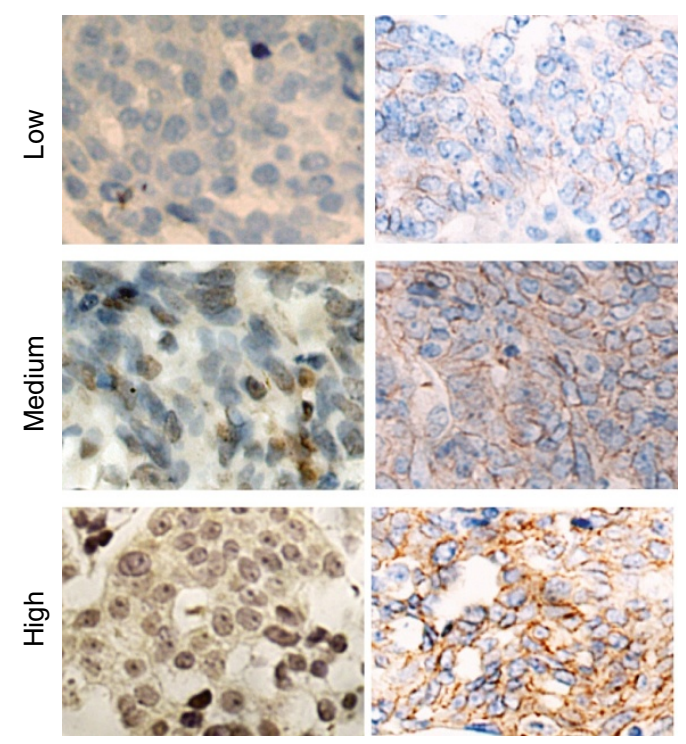

Figure 4 Correlation between the expression levels of BRCA1 and AGTR1 in ovarian cancer samples. A, Correlation between the BRCA1 and AGTR1 protein levels in 63 human ovarian cancer tissue samples. Intensity of staining was divided into 10 units. B, Examples of immunohistochemical staining showing the positive correlation between the expression levels of BRCA1 and AGTR1 in ovarian cancers. Magnification is $400 \times$. 
ovarian cancer specimens; and (iii) $B R C A 1$ activation was effective at inducing $A G T R 1$ expression in primary ovarian cancer cells. These results suggest that BRCA1 may be a potential trigger for AGTR1. Interestingly, the activation effects of $B R C A 1$ were primarily observed in cells originating from primary ovarian cancer, especially $B R C A 1$-mutated ovarian cancer cells, but $293 \mathrm{~T}$ and SKOV3 cells were insensitive to the overexpression or knockdown of BRCA1. Accordingly, a specific intracellular environment may exist, and AGTR1 expression is likely to be the long-term result of a complex interaction of multiple factors in BRCA1related ovarian cancer. Notably, a body of evidence suggests that there is extensive crosstalk among BRCA1 signaling pathways and hormone receptors. For example, the insulinlike growth factor 1 receptor (IGF1R) gene is a downstream target for $B R C A 1$, as wild-type BRCA1 expression suppresses promoter activity and endogenous IGF1R levels [3]; $B R C A 1$ can lead to degradation of the progesterone receptor by counteracting the action of progesterone; multiple mechanisms are involved in BRCA1-mediated estrogen receptor repression $[19,20]$. However, to date, there have been few reports about the interactions between BRCA1 and AGTR1. Moreover, mounting evidence indicates that BRCA1 tumor suppressor gene dysfunction has an important role in promoting cell proliferation and survival [14,21-23]. The mechanism may involve: 1) inducing insulin-like growth factor 1 expression [3,24] in an estrogen receptor $\alpha$-dependent manner [24,25]; and 2) stimulating progesterone receptor activity by facilitating progesterone binding to the progesterone response elements [26]. AGTR1 also plays a key role in regulating cell growth and proliferation during the initiation and progression of cancer $[27,28]$. Therefore, the discovery of BRCA1-mediated AGTR1 expression will stimulate new interest in the study of BRCA1-related cellular proliferation, although the details remain unclear. To date, it is not fully understood how BRCA1 activates AGTR1 gene expression at the molecular level. However, some insight may be gained by further study, and preliminary data suggest that a direct interaction between miR-155 and AGTR1 (Additional file 5: Figure S3, methods shown in Additional file 3). Specifically, miR-155 is a regulatory target for BRCA1 [29,30]; BRCA1 knockdown results in a two- to three-fold increase in miR155 levels [29,31], which may be involved in AGTR1 transcriptional repression, but there are still some details that need to be considered.

\section{Conclusion}

Our results indicate that $B R C A 1$ may be a potential regulator of AGTR1 in ovarian cancer cells. Based on these findings, there are some interesting issues that need to be considered in future studies, such as how BRCA1 affects AGTR1 transcription and whether other factors could cooperate with BRCA1 in controlling AGTR1 expression.
Also, the complex interactions between $B R C A 1$ and AGTR1 signaling pathways need to be clarified. All of this may improve our understanding of the basic molecular mechanism of BRCA1-related ovarian cancer.

\section{Additional files}

Additional file 1: Table S1. Clinical characteristics for the 15 BRCA1-
mutated serous ovarian cancer patients.

Additional file 2: Figure S1. Cell proliferation rate of primary ovarian cancer cells.

Additional file 3: Supplementary methods.

Additional file 4: Figure S2. The efficiency of BRCA1 knockdown and overexpression.

Additional file 5: Figure S3. The interaction between miR-155 and AGTR1.

\section{Abbreviations}

AGTR1: Angiotensin II type 1 receptor; PCR: Polymerase chain reaction; shRNAs: Short hairpin RNAs.

\section{Competing interests}

The authors declare that they have no competing interests.

\section{Authors' contributions}

$\mathrm{DL}$ and QY conceived of the study, participated in its design and drafted the manuscript. DL, FFB and CC carried out data acquisition and interpretation. FFB, CC and CYL participated in the design of the study and performed the statistical analysis. All authors read and approved the final manuscript.

\section{Acknowledgements}

This work was supported by the 973 Program of China (No. 2011CB933504), Natural Science Foundation of China (No. 81071072) and the Higher Specialized Research Fund for Doctoral Program of Ministry of Education of China (No. 20122104110027).

\section{Author details}

'Department of Obstetrics and Gynecology, Shengjing Hospital, China Medical University, Shenyang 110004, China. ${ }^{2}$ Department of Pathology, Chinese PLA General Hospital, Beijing 100853, China. ${ }^{3}$ Department of Histology and Embryology, Institute of Basic Medical Sciences, Chinese Academy of Medical Sciences, School of Basic Medicine, Peking Union Medical College, Beijing 100005, China.

Received: 18 October 2013 Accepted: 6 December 2013 Published: 9 December 2013

\section{References}

1. Siegel R, Naishadham D, Jemal A: Cancer statistics, 2012. CA Cancer J Clin 2012, 62:10-29.

2. Pruthi $\mathrm{S}$, Gostout $B S$, Lindor NM: Identification and management of women with BRCA mutations or hereditary predisposition for breast and ovarian cancer. Mayo Clin Proc 2010, 85:1111-1120.

3. Werner $\mathrm{H}$, Bruchim I: IGF-1 and BRCA1 signalling pathways in familial cancer. Lancet Oncol 2012, 13:e537-e544.

4. Herichova I, Szantoova K: Renin-angiotensin system: upgrade of recent knowledge and perspectives. Endocr Regul 2013, 47:39-52.

5. Piastowska-Ciesielska AW, Płuciennik E, Wójcik-Krowiranda K, Bieńkiewicz A, Bednarek A, Ochędalski T: Analysis of the expression of angiotensin II type 1 receptor and VEGF in endometrial adenocarcinoma with different clinicopathological characteristics. Tumour Biol 2012, 33:767-774.

6. Piastowska-Ciesielska AW, Płuciennik E, Wójcik-Krowiranda K, Bieńkiewicz A, Nowakowska M, Pospiech K, Bednarek AK, Domińska K, Ochędalski T: Correlation between VEGFR-2 receptor kinase domain-containing receptor (KDR) mRNA and angiotensin II receptor type 1 (AT1-R) mRNA in endometrial cancer. Cytokine 2013, 61:639-644. 
7. Kikkawa F, Mizuno M, Shibata K, Kajiyama H, Morita T, Ino K, Nomura S, Mizutani S: Activation of invasiveness of cervical carcinoma cells by angiotensin II. Am J Obstet Gynecol 2004, 190:1258-1263.

8. De Nuccio I, Salvati G, Genovesi G, Paolini P, Marcellini L, Schiavello V, Re M: Physiopathology of the renin-angiotensin system in the ovary. Minerva Endocrinol 1999, 24:77-81.

9. Ino K, Shibata K, Kajiyama H, Yamamoto E, Nagasaka T, Nawa A, Nomura S, Kikkawa F: Angiotensin II type 1 receptor expression in ovarian cancer and its correlation with tumour angiogenesis and patient survival. Br J Cancer 2006, 94:552-560.

10. Suganuma T, Ino K, Shibata K, Kajiyama H, Nagasaka T, Mizutani S, Kikkawa F: Functional expression of the angiotensin II type 1 receptor in human ovarian carcinoma cells and its blockade therapy resulting in suppression of tumor invasion, angiogenesis, and peritoneal dissemination. Clin Cancer Res 2005, 11:2686-2694.

11. Song L, Zhang SL, Bai KH, Yang J, Xiong HY, Li X, Liu T, Liu HR: Serum agonistic autoantibodies against type-1 angiotensin II receptor titer in patients with epithelial ovarian cancer: a potential role in tumor cell migration and angiogenesis. J Ovarian Res 2013, 6:22.

12. Yang Q, Su Q, Wang G, Bi F, Sa R: Effect of AT1R knockdown on ishikawa cell proliferation induced by estrogen. Arch Gynecol Obstet 2012, 286:481-487.

13. Chen X, Meng Q, Zhao Y, Liu M, Li D, Yang Y, Sun L, Sui G, Cai L, Dong X: Angiotensin II type 1 receptor antagonists inhibit cell proliferation and angiogenesis in breast cancer. Cancer Lett 2013, 328:318-324.

14. Burga LN, Tung NM, Troyan SL, Bostina M, Konstantinopoulos PA, Fountzilas $H$, Spentzos D, Miron A, Yassin YA, Lee BT, Wulf GM: Altered proliferation and differentiation properties of primary mammary epithelial cells from BRCA1 mutation carriers. Cancer Res 2009, 69:1273-1278.

15. Bi FF, Li D, Yang Q: Promoter hypomethylation, especially around the E26 transformation-specific motif, and increased expression of poly (ADP-ribose) polymerase 1 in BRCA-mutated serous ovarian cancer. BMC Cancer 2013, 13:90

16. Simard J, Tonin P, Durocher F, Morgan K, Rommens J, Gingras S, Samson C, Leblanc JF, Bélanger C, Dion F, Liu Q, Skolnick M, Goldgar D, ShattuckEidens D, Labrie F, Narod SA: Common origins of BRCA1 mutations in Canadian breast and ovarian cancer families. Nat Genet 1994, 8:392-398.

17. Szlosarek PW, Grimshaw MJ, Kulbe H, Wilson JL, Wilbanks GD, Burke F, Balkwill FR: Expression and regulation of tumor necrosis factor alpha in normal and malignant ovarian epithelium. Mol Cancer Ther 2006, 5:382-390.

18. Suvà ML, Riggi N, Bernstein BE: Epigenetic reprogramming in cancer. Science 2013, 339:1567-1570

19. Ma Y, Fan S, Hu C, Meng Q, Fuqua SA, Pestell RG, Tomita YA, Rosen EM: $B R C A 1$ regulates acetylation and ubiquitination of estrogen receptoralpha. Mol Endocrinol 2010, 24:76-90.

20. Ma Y, Hu C, Riegel AT, Fan S, Rosen EM: Growth factor signaling pathways modulate $B R C A 1$ repression of estrogen receptor-alpha activity. $\mathrm{Mol}$ Endocrinol 2007, 21:1905-1923.

21. Garcia Al, Buisson M, Bertrand P, Rimokh R, Rouleau E, Lopez BS, Lidereau R, Mikaelian I, Mazoyer S: Down-regulation of BRCA1 expression by miR-146a and miR-146b-5p in triple negative sporadic breast cancers. EMBO Mol Med 2011, 3:279-290.

22. Promkan M, Liu G, Patmasiriwat $P$, Chakrabarty S: BRCA1 modulates malignant cell behavior, the expression of survivin and chemosensitivity in human breast cancer cells. Int J Cancer 2009, 125:2820-2828.

23. Srinivas $G$, Annab LA, Gopinath $G$, Banerii A, Srinivas P: Antisense blocking of BRCA1 enhances sensitivity to plumbagin but not tamoxifen in BG-1 ovarian cancer cells. Mol Carcinog 2004, 39:15-25.

24. Kang HJ, Yi YW, Kim HJ, Hong YB, Seong YS, Bae I: BRCA1 negatively regulates IGF-1 expression through an estrogen-responsive element-like site. Cell Death Dis 2012, 3:e336.

25. Wen J, Li R, Lu Y, Shupnik MA: Decreased BRCA1 confers tamoxifen resistance in breast cancer cells by altering estrogen receptorcoregulator interactions. Oncogene 2009, 28:575-586.

26. Katiyar P, Ma Y, Riegel A, Fan S, Rosen EM: Mechanism of BRCA1-mediated inhibition of progesterone receptor transcriptional activity. Mol Endocrinol 2009, 23:1135-1146.

27. Arrieta O, Pineda-Olvera B, Guevara-Salazar P, Hernández-Pedro N, MoralesEspinosa D, Cerón-Lizarraga TL, la Rosa CH G-D, Rembao D, Segura-Pacheco B, Sotelo J: Expression of AT1 and AT2 angiotensin receptors in astrocytomas is associated with poor prognosis. Br J Cancer 2008, 99:160-166.
28. Redondo-Müller MA, Stevanovic-Walker M, Barker S, Puddefoot JR, Vinson GP: Anti-cancer actions of a recombinant antibody (R6313/G2) against the angiotensin II AT1 receptor. Endocr Relat Cancer 2008, 15:277-288.

29. Chang S, Wang RH, Akagi K, Kim KA, Martin BK, Cavallone L, Kathleen Cuningham foundation consortium for research into familial breast cancer (kConFab), Haines DC, Basik M, Mai P, Poggi E, Isaacs C, Looi LM, Mun KS, Greene MH, Byers SW, Teo SH, Deng CX, Sharan SK: Tumor suppressor BRCA1 epigenetically controls oncogenic microRNA-155. Nat Med 2011, 17:1275-1282

30. Stefansson OA, Esteller M: BRCA1 as a tumor suppressor linked to the regulation of epigenetic states: keeping oncomiRs under control. Breast Cancer Res 2012, 14:304.

31. Chang S, Sharan SK: Epigenetic control of an oncogenic microRNA miR-155, by BRCA1. Oncotarget 2012, 3:5-6.

doi:10.1186/1757-2215-6-89

Cite this article as: $\mathrm{Bi}$ et al.: Regulation of angiotensin II type 1 receptor expression in ovarian cancer: a potential role for BRCA1. Journal of Ovarian Research 2013 6:89.

\section{Submit your next manuscript to BioMed Central and take full advantage of:}

- Convenient online submission

- Thorough peer review

- No space constraints or color figure charges

- Immediate publication on acceptance

- Inclusion in PubMed, CAS, Scopus and Google Scholar

- Research which is freely available for redistribution 